\title{
PENGARUH NILAI INDIVIDU TERHADAP NILAI ORGANISASI DENGAN NILAI SPIRITUAL SEBAGAI MEDIATOR
}

\author{
Elang Kusumo ${ }^{1}$, Sutoha $^{2}$, Albertha Dwi Setyorini ${ }^{3}$, Hermanto Yaputra ${ }^{4}$ \\ Email: elangkusumo1551@gmail.com ${ }^{1}$,toha_clg@yahoo.com², \\ alberthads2017@yahoo.com ${ }^{3}$, hermanto.yaputra@trisakti.ac.id ${ }^{4}$ \\ ${ }^{1,2,3,4}$ Program Studi Service Management, Fakultas Ekonomi dan Bisnis, \\ Universitas Trisakti
}

\begin{abstract}
The values of organization usually reflect the individual values of the founders, these values are recognized and preserved by members of the organization. The individual values include social values, moral values and spiritual values, which from an early age have been embedded and grow in the family and social environment. The value of the organization is also heavily influenced by the values of the individual founders. The purpose of this study is to evaluate the organizational values and the implementations into organizational activities and processes, and individual value as determinant variables which are social values, moral values and spiritual values as mediating variable. Quantitative descriptive method is used in this study, by making exposure, to explain the situation and facts found in the field, and evaluate the relationship between variables. The respondents are consisted of the employee of company in total 155 respondents. The results of this study indicated that social values and moral values as individual values, as antecedents of organizational values as well, have a positive and significant effect on organizational values. Meanwhile, between social values and organizational values through spiritual values as a mediating variable, there is a positive and insignificant effect, and between moral values and organizational values through spiritual values as a mediating variable, there is a positive and significant effect.
\end{abstract}

\begin{abstract}
Abstrak: Nilai Organisasi biasanya mencerminkan nilai-nilai individu para pendirinya, nilai-nilai tersebut diakui dan dilestarikan oleh para anggota organisasi. Nilai individu meliputi nilai sosial, nilai moral dan nilai spiritual, yang sejak dini telah tertanam dan tumbuh dalam keluarga dan lingkungan sosial. Nilai organisasi sangat dipengaruhi oleh nilai-nilai individu pendirinya. Tujuan dari penelitian ini adalah untuk mengevaluasi nilai organisasi dan implementasinya ke dalam kegiatan dan proses organisasi, serta nilai individu sebagai variable determinan, yaitu nilai sosial, nilai moral dan nilai spiritual sebagai variabel mediasi. Metode deskriptif kuantitatif digunakan dalam penelitian ini, dengan membuat paparan, untuk menjelaskan situasi dan fakta yang ditemukan di lapangan, dan mengevaluasi hubungan antar variabel. Responden terdiri dari karyawan perusahaan yang berlokasi di Jabodetabek dan berjumlah 155 responden. Penelitian dilakukan dalam periode bulan September sampai November 2021. Hasil penelitian menunjukkan bahwa nilai individu berupa nilai sosial dan nilai moral sebagai anteseden, berpengaruh secara positif dan signifikan terhadap nilai organisasi. Sedangkan antara nilai sosial terhadap nilai organisasi melalui nilai spiritual sebagai variabel mediasi, terdapat pengaruh positif dan tidak signifikan dan antara nilai moral terhadap nilai organisasi melalui nilai spiritual sebagai variabel mediasi terdapat pengaruh positif dan signifikan.
\end{abstract}

Keywords: organization value, social value, moral value, spiritual value. 


\section{PENDAHULUAN}

Aktifitas organisasi/perusahaan berbasis pada visi dan misi yang telah ditetapkan oleh pendiri, dan kinerja karyawan pada organisasi tersebut, dipengaruhi oleh nilai individu masing-masing karyawan, selain dipengaruhi oleh nilai individu, kinerja karyawan juga dipengaruhi oleh nilai organisasi yang merupakan nilai dari pendiri organisasi tersebut (Gorenak \& Ferjan, 2015). Nilai organisasi bukan hanya nilai yang muncul dari organisasi itu sendiri, tetapi juga berasal dari nilai individu yang bercampur bersama nilai organisasi, sehingga berkembang nilai-nilai baru pada organisasi tersebut. Pada awalnya nilai organisasi bertumbuh dengan berbasis pada nilai-nilai pribadi pendiri atau pendiri suatu organisasi, namun bersamaan dengan tumbuh dan berkembangannya organisasi, nilai-nilai pada organisasi berubah karena adanya pengalaman baru yang memunculkan nilai-nilai baru pada organisasi (Gorenak \& Ferjan, 2015).

Nilai organisasi (organizational value) adalah seperangkat "keyakinan" yang dimiliki oleh pendiri organisasi, sebagai nilai kebenaran yang bersifat permanen, dan menjadi nilai-nilai yang diinginkan, dapat diterima, dan didukung oleh semua individu di dalam organisasi (Gorenak et al., 2020). Nilai organisasi berbeda dengan nilai lainnya, karena merupakan sekumpulan nilai bersifat kolektif yang hidup dan menjadi dasar aktivitas dan kinerja organisasi (Bourne et al., 2019). Nilai individu (pribadi) pendiri atau pemilik perusahaan merupakan anteseden bagi nilai organisasi, yang berproses, diturunkan dari atas (pemilik/pendiri) kepada manajemen organisasi/perusahaan, untuk kemudian meresap ke seluruh aktifitas dan kegiatan organisasi (Adla et al., 2020).

Nilai sosial (social value) merupakan cerminan prinsip, perilaku, sikap Individu yang membentuk pandangan, pemahaman, tujuan hidup yang memengaruhi keputusan individu. Nilai social ini berkembang dalam situasi, sisi kehidupan material dan spiritual individu/manusia, yang pada akhirnya akan memberikan makna pada kehidupan individu tersebut serta masayarakat sekitarnya. Persepsi nilai sosial yang tumbuh dalam diri manusia merupakan hasil interaksi sesama manusia yang adalah makhluk social, untuk kemudian membentuk keseluruhan nilai dalam diri manusia/individu (Bolat \& Korkmaz, 2021).

Nilai moral (moral value) Menurut Kamus

Besar Bahasa Indonesia (KBBI), moral didefinisikan sebagai hal yang menentukan baik atau buruknya tingkah laku manusia. Pesan yang disampaikan di dalam nilai moral adalah berupa nasehat tentang perbuatan baik atau buruk. Prinsip baik dan buruk dikaitkan dengan perilaku dan cara berpikir manusia, pesan pada nilai moral ditujukan agar kehidupan manusia menjadi lebih baik (Nasir et al., 2019).

Nilai spiritual (spiritual value) adalah bagian dari nilai budaya, yang terkait dengan budaya sosial dan keyakinan serta nilai-nilai kebaikan sesorang. Nilai spiritual dapat tumbuh berkembang tidak hanya di tempat spiritual (tempat suci) tetapi juga di tempat lainnya, tetapi perkembangan nilai spiritual lebih kuat akan terjadi ketika seseorang berkunjung/berada di tempat-tempat suci. Individu dapat lebih mudah merasakan dan mengalami sentuhan spiritual ketika berada di tempat-tempat yang suci (Huang et al., 2020).

\section{METODE}

Variabel yang dievaluasi dan dianalisis adalah nilai sosial (social value) dan nilai moral (moral value) sebagai independent variable dan nilai spriritual (spiritual value) sebagai variable mediator serta nilai organisasi (organizational value) sebagai variable dependen.

Pendekatan kuantitatif digunakan dalam studi ini, dengan melakukan teknik analisis Partial Least Square - Structural Equation Model (PLS-SEM). Data yang dikumpulkan menggunakan kuesioner dengan 4 skala likert, untuk kemudian dianalisis menggunakan perhitungan statistik. Pendekatan kuantitatif akan melakukan dan mencari penjelasan dan prediksi yang dihasilkan dari data terhadap objek dan subjek penelitian (Creswell, 2014). Pengumpulan data dilakukan dalam periode Oktober-November 2021 terhadap responden yang merupakan pegawai/karyawan perusahaan yang berdomisili di seputar Jabodetabek. Teknik purposive sampling digunakan untuk menentukan sampel penelitian yang bertujuan untuk memperoleh data yang lebih presentatif. Dengan menggunakan model struktural pada penelitian ini, yang terdiri dari 4 variabel, maka ditentukan ukuran sampel sebesar sepuluh kali jumlah total jalur struktural yaitu: 4 × $10=40$ sampel, tetapi untuk memperoleh hasil yang lebih tajam, maka pada penelitian ini 
menggunakan 155 sampel (Hair et al., 2019). Kuesioner yang disebarkan menggunakan 4 Skala Likert dilakukan untuk mengukur nilai sosial, nilai moral dan nilai spritual mengacu pada skala pengukuran dari Vveinhardt \& Gulbovaite (2015), sedangkan nilai organisasi diukur menggunakan skala pengukuran dari Gorenak \& Ferjan (2015). Pengolahan data dilakukan dengan analisis Structural Equation Modeling (SEM) yang berbasis varians yaitu Partial Least Square (PLS), dan pengolah data menggunakan Software Smart-PLS 3.

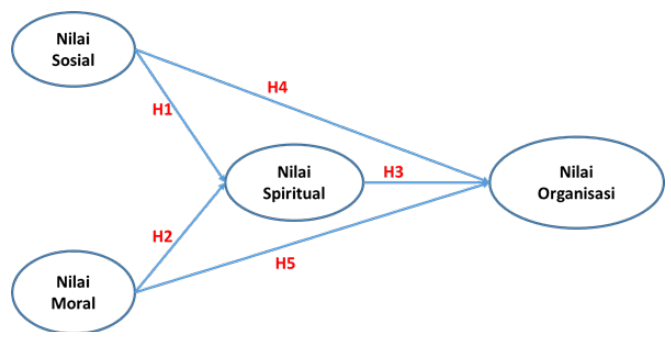

Gambar 1. Model Penelitian

\section{HASIL DAN PEMBAHASAN}

Pada metode PLS-SEM dilakukan 2 teknik analisis yaitu:

1. Analisis Outer Model (Measurement Model) dilakukan untuk memastikan bahwa measurement yang digunakan dinyatakan layak untuk dijadikan pengukur (valid dan reliabel). Analisa model ini dilakukan untuk mengetahui hubungan variabel laten dengan indikatorindikatornya.

2. Analisis Inner Model (Struktural Model). Analisis Inner Model dilakukan untuk menggambarkan hubungan antara variabel laten berdasarkan pada substantive theory. (Ghozali, 2021).

\section{Hasil Uji Measurment Model}

Pengukuran Factor Loading (Outer Loading) dilakukan untuk mengetahui nilai yang dihasilkan oleh setiap indikator dengan mengukur variablenya (nilai factor loading setiap indokator harus di atas 0.7) (Hair et al., 2019) Semua indikator pada setiap variabel yang diukur menunjukkan nilai di atas 0.7 , sehingga disimpulkan bahwa semua indikator dapat digunakan untuk mengukur variabelnya.

Pengukuran Average Variance Extracted $(A V E)$ mengetahui banyaknya varians yang dapat ditangkap oleh konstruknya. Nilai AVE harus lebih besar (>0.5) (Hair et al., 2019) pada Tabel 1.

\begin{tabular}{|c|c|}
\hline & $\begin{array}{c}\text { Average Variance Extracted } \\
\text { (AVE) }\end{array}$ \\
\hline Nilai Moral & 0.658 \\
\hline Nilai Organisasi & 0.632 \\
\hline Nilai Sosial & 0.685 \\
\hline Nilai Spriritual & 0.669 \\
\hline
\end{tabular}

Pengukuran Forner Lacker Criterion (Tabel 3) digunakan untuk mengetahui korelasi antara variabel dengan variabel lain, dan nilainya tidak boleh lebih besar dari korelasi antara variabel itu sendiri. Hasilnya korelasi antara nilai variabel dengan variabel lain, lebih kecil dibanding nilai korelasi variabel dengan variable itu sendiri.

Tabel 3. Fornel Lacker Criterion
Nilai Nilai Nilai Nilai

\begin{tabular}{|c|c|c|c|c|}
\hline & $\begin{array}{l}\text { Nilai } \\
\text { Moral } \\
\end{array}$ & $\begin{array}{c}\text { Nilai } \\
\text { Organisasi }\end{array}$ & $\begin{array}{l}\text { Nilai } \\
\text { Sosial } \\
\end{array}$ & $\begin{array}{c}\text { Nilai } \\
\text { Spriritual }\end{array}$ \\
\hline Nilai Moral & 0.811 & & & \\
\hline $\begin{array}{l}\text { Nilai } \\
\text { Organisasi }\end{array}$ & 0.769 & 0.795 & & \\
\hline $\begin{array}{l}\text { Nilai Sosial } \\
\text { Nilai }\end{array}$ & 0.725 & 0.769 & 0.828 & \\
\hline Spriritual & 0.776 & 0.758 & 0.650 & 0.818 \\
\hline
\end{tabular}

Pengukuran Cross Loading, dimaksudkan mengukur korelasi antara indikator dengan indikator lain, dibandingkan dengan korelasi antara indikator dan indikator itu sendiri. Nilai yang diharapkan bahwa setiap indikator memiliki nilai loading lebih tinggi (lebih besar) untuk konstruk yang diukur dibandingkan dengan nilai loading ke konstruk yang lain.

Hasil pengukuran Factor Loading, Average Variance Extracted, Fornel Lacker Criterion dan Cross Loading, bertujuan untuk menguji validitas dengan hasil bahwa semua indikator yang digunakan dinilai mampu mengukur semua variabel yang digunakan dalam penelitian ini.

Hasil uji reliabilitas pada penelitian ini adalah bahwa instrumen yang digunakan dalam penelitian ini ampuh dan mampu mengungkap informasi di lapangan, hal ini terlihat dari nilai Cronbach's Alpha dan Composite Reliability, kedua nilai tersebut berada di atas 0.7 (Hair et al., 2019) pada Tabel 4. 
Tabel 4. Nilai Cronbach's Alpha dan

\begin{tabular}{lcl}
\multicolumn{3}{c}{ Composite Reliability } \\
\hline & $\begin{array}{c}\text { Cronbach's } \\
\text { Alpha }\end{array}$ & $\begin{array}{l}\text { Composite } \\
\text { Reliability }\end{array}$ \\
\hline Nilai Moral & 0.869 & 0.905 \\
Nilai Organisasi & 0.882 & 0.911 \\
Nilai Sosial & 0.844 & 0.896 \\
Nilai Spriritual & 0.835 & 0.890 \\
\hline
\end{tabular}

Instrumen yang digunakan untuk mengukur setiap variabel pada penelitian ini, sudah reliabel, sesuai dan mampu mengungkap informasi di lapangan.

\section{Hasil Uji Struktural Model}

Uji ini dimaksudkan untuk menguji hubungan antara variable independen (eksogen) dan variable dependen (endogen), serta menguji seberapa fit model yang diteliti. Pengujian ini dilakukan dengan melihat nilai $R$-square, Path Coefficients, T-Statistic, dan Model Fit.

\section{R-square}

Hasil pengukuran Nilai $R$-Square seperti terlihat pada Tabel 5 .

Tabel 5. Nilai R-Square

\begin{tabular}{lcc}
\hline & $R$ Square & $R$ Square Adjusted \\
\hline Nilai & & \\
Organisasi & 0.724 & 0.719 \\
Nilai & & \\
Spiritual & 0.619 & 0.614 \\
\hline
\end{tabular}

Nilai organisasi dapat dijelaskan oleh variabel independen berupa nilai sosial dan nilai moral, bersama dengan nilai spiritual (variabel mediating) sebesar $72.4 \%$ (0.724), sedangkan sisanya $27.6 \%(0.276)$ dijelaskan oleh variabel lain yang tidak diteliti pada model penelitian ini.

Nilai spiritual dapat dijelaskan oleh variable independen berupa nilai sosial dan nilai moral sebesar $61.9 \% \quad(0.619)$, sedangkan sisanya $38.1 \%$ (0.381) dijelaskan oleh variabel lain yang tidak diteliti pada model penelitian ini.

Nilai $R$-square di atas $0.5 \quad(50 \%)$ menunjukkan bahwa model penelitian dianggap kuat sehingga dapat disimpulkan model yang digunakan pada penelitian ini dianggap Fit.

\section{Path Coefficients \& T-Statistic}

Hasil uji Path Coeffients ini dimaksudkan untuk mengetahui arah hubungan langsung antara variable (positif atau negatif), seperti pada data pada Tabel 6 .
Tabel 6. Nilai Path Coefficients

\begin{tabular}{lll}
\hline & Nilai & Nilai \\
& Organisasi & Spriritual \\
\hline Nilai Moral & 0.241 & 0.643 \\
Nilai Sosial & 0.386 & 0.184 \\
Nilai Spiritual & 0.319 & \\
\hline
\end{tabular}

Sedangkan uji T-Statistic dimaksudkan untuk mengetahui signifikansi hubungan langsung antara variabel, untuk dapat dinyatakan signifikan maka nilai harus di atas $1.96(>1.96)$ pada Tabel 7.

Tabel 7. Nilai T-Statistic

\begin{tabular}{lc}
\hline & $\begin{array}{c}\mathrm{T} \\
\text { Statistics }\end{array}$ \\
\hline Nilai Moral $\rightarrow$ Nilai Organisasi & 2.310 \\
Nilai Moral $\rightarrow$ Nilai Spiritual & 7.898 \\
Nilai Sosial $\rightarrow$ Nilai Organisasi & 4.655 \\
Nilai Sosial $\rightarrow$ Nilai Spiritual & 2.032 \\
Nilai Spiritual $\rightarrow$ Nilai Organisasi & 3.450 \\
\hline
\end{tabular}

Hasil analisis Path Coefficients dan $T$ Statistic menunjukkan hubungan/pengaruh langsung sebagai berikut:

$\mathrm{H} 1$ = Nilai sosial berpengaruh positif $(0.184)$ dan signifikan (2.032) terhadap nilai spiritual.

$\mathrm{H} 2$ = Nilai moral berpengaruh positif (0.643) dan signifikan (7.898) terhadap nilai spiritual.

H3 = Nilai spiritual berpengaruh positif (0.319) dan signifikan (3.450) terhadap nilai organisasi. $\mathrm{H} 4=$ Nilai sosial berpengaruh positif $(0.386)$ dan signifikan (4.655) terhadap nilai organisasi.

H5 = Nilai moral berpengaruh positif $(0.241)$ dan signifikan (2.310) terhadap nilai organisasi.

\section{Pengaruh Tidak Langsung}

Untuk mengetahui pengaruh tidak langsung variable independen terhadap variabel dependen melalui variabel mediasi, terlihat dari analisis Specific Indirect effects pada Tabel 8.

Tabel 8. Specific Indirect Effects

\begin{tabular}{lccc}
\hline & $\begin{array}{c}\text { Original } \\
\text { Sample }\end{array}$ & $\begin{array}{c}T \\
\text { Statistic }\end{array}$ & $\begin{array}{c}P \\
\text { Values }\end{array}$ \\
\hline H6. Nilai Moral & & & \\
$\rightarrow$ Nilai & & & \\
Spiritual $\rightarrow$ & & & \\
Nilai Organisasi & 0.205 & 3.023 & 0.003 \\
$\begin{array}{l}\text { H7. Nilai Sosial } \\
\rightarrow \text { Nilai }\end{array}$ & & & \\
$\quad$ Spiritual $\rightarrow$ & & & \\
Nilai Organisasi & 0.059 & 1.878 & 0.061 \\
\hline
\end{tabular}


H6: Terdapat pengaruh positif (0.205) dan signifikan (3.023, di atas 1.96 , dan $\mathrm{P}$ values 0.003) antara Nilai Moral terhadap Nilai Organisasi melalui Nilai Spiritual sebagai variable mediasi.

H7: Terdapat pengaruh positif (0.059) dan tidak signifikan (T Statistic 1.878, di bawah 1.96, dan $P$ Values 0.061) antara Nilai Sosial terhadap nilai organisasi melalui nilai spiritual sebagai variable mediasi.

\section{Peran Variable Mediasi}

Peran variable mediasi (nilai spiritual) pada penelitian ini, dengan cara membandingkan hubungan langsung dan tidak langsung terhadap variabel dependen (nilai organisasi), hasilnya dijelaskan pada Tabel 9.

Tabel 9. Peran Variable Mediator

\begin{tabular}{lll}
\hline Langsung & Tidak langsung & Hasil \\
\hline H4 Nilai & H6= Terdapat & Nilai Spiritual \\
Sosial & pengaruh positif & sebagai Variable \\
berpengaruh & $(0.059)$ dan tidak & Mediasi tidak \\
positif & signifikan (T & memiliki (tidak ada) \\
$(0.386)$ dan & Statistic 1.878, di & efek mediasi $($ No \\
signifikan & bawah 1.96, dan & Mediation). Karena \\
$(4.655)$ & P Values 0.061) & ketika variable \\
terhadap & antara Nilai & mediasi \\
Nilai & Sosial terhadap & dimunculkan, tidak \\
Organisasi & Nilai Organisasi & membawa pengaruh \\
& melalui Nilai & signifikan terhadap \\
& Spiritual & hubungan variable \\
& & independent dan \\
& H7 = Terdapat & Variable Dependen \\
\hline H5 $=$ & pengaruh positif & sebagai Variable \\
Nilai Moral & $(0.205)$ dan & Mediasi tidak \\
berpengaruh & signifikan (3.023, & berperan penuh \\
positif & di atas 1.96, dan & dalam membawa \\
(0.241) dan & P values 0.003) & efek mediasi (ada \\
signifikan & antara Nilai & atau tidak ada \\
$(2.310)$ & Moral terhadap & variable mediasi, \\
terhadap & Nilai Organisasi & pengaruh hubungan \\
Nilai & melalui Nilai & antara variable \\
Organisasi & Spiritual sebagai & independent dan \\
& variable mediasi. & variable dependent \\
& & hasilnya sama) \\
\hline
\end{tabular}

Berdasarkan hasil perbandingan antara H4 (hubungan langsung antara nilai sosial terhadap nilai organisasi) dengan H6 (hubungan tidak langsung antara nilai sosial terhadap nilai organisasi, melalui variable mediasi nilai spiritual) ditemukan hasil bahwa nilai spiritual tidak memberikan pengaruh signifikan (no mediation effect).

Peran variable mediasi berikutnya dapat dilihat dari perbandingan antara H5 (hubungan langsung nilai moral terhadap nilai organisasi) dengan $\mathrm{H} 7$ (hubungan tidak langsung antara nilai moral terhadap nilai organisasi, melalui variabel mediasi nilai spiritual), terlihat hasil perbandingannya menunjukkan nilai spiritual sebagai variabel mediasi, tidak berperan penuh dalam membawa efek mediasi (ada atau tidak ada variabel mediasi, pengaruh hubungan antara variabel independen dan variabel dependen hasilnya sama).

\section{Model Fit}

Analisis model fit dilakukan untuk mengetahui seberapa baik model yang diteliti dengan hasil nilai NFI sebesar 0.774 (77.4\%), menunjukkan bahwa model penelitian dianggap FIT (di atas 50\%).

\section{SIMPULAN \& SARAN Simpulan}

Berdasarkan hasil analisis dan pembahasan di atas didapat simpulan sebagai berikut:

1. Terdapat 2 variable independen (eksogen) yaitu nilai sosial dan nilai moral yang diukur terhadap variable dependen (endogen) yaitu nilai organisasi, melalui variabel mediating yaitu nilai spiritual.

2. Semua variable independen (eksogen) dinyatakan valid dan reliabel.

3. Model yang digunakan pada penelitian ini dinyatakan fit/kuat.

4. Nilai sosial dan nilai moral secara langsung berpengaruh secara positif dan signifikan terhadap terbentuknya nilai organisasi, hal ini menunjukkan bahwa nilai individu karyawan dalam organisasi sangat mempengaruhi dan memberi dampak pada pembentukan nilai organisasi, yang pada akhirnya akan memengaruhi aktifitas dan operasional perusahaan. Hal ini penting bagi organisasi untuk memberi perhatian khusus pada nilai individu karyawan dan tidak hanya nilai individu pendiri.

5. Nilai spiritual sebagai variable mediating tidak memberi pengaruh hubungan antara nilai sosial dan nilai organisasi, terlihat dari nilai pengaruh yang tidak signifikan. sehingga nilai sosial tanpa melalu nilai spiritual sudah mampu memengaruhi nilai organisasi, hal ini sangat mungkin terjadi, karena kemungkinan di dalam nilai sosial terdapat nilai spiritual, fakta ini dapat dijadikan rekomendasi penelitian berikutnya. 


\section{Saran}

Penelitian ini menganalisis pengaruh dari dua variabel nilai individu (nilai sosial dan nilai moral), sehingga perlu dilakukan analisis dengan menggunakan variabel lain dari nilai individu (misalnya nilai kepemimpinan, nilai pelayanan dan lain-lain) agar lebih komprehensif. Perlu dilakukan analisis dengan pendekatan deskriptif kualitatif sehingga hasilnya dapat melengkapi penelitian ini. 


\section{Kepustakaan}

Adla, L., Eyquem-Renault, M., \& GallegoRoquelaure, V. (2020). From the leader's values to organizational values: Toward a dynamic and experimental view on value work in SMEs. Management (France), 23(1), 81-101. https://doi.org/10.37725/mgmt.v23.4418

Bolat, Y., \& Korkmaz, C. (2021). Social Values and Life Skills as Predictors of Organizational Culture: A Study on Teachers. SAGE Open, 11(2). https://doi.org/10.1177/21582440211023 179

Bourne, H., Jenkins, M., \& Parry, E. (2019). Mapping Espoused Organizational Values. Journal of Business Ethics, 159(1), 133-148. https://doi.org/10.1007/s10551-0173734-9

Creswell, J. W. (2014). Research Design, Qualitative, Quantitative and Mixed Methods Approaches (4th ed.).

Ghozali, I. (2021). Partial Least Squares, Konsep, Teknik, dan Aplikasi Menggunakan Program SmartPLS 3.2.9 untuk peneliti. In Universitas Diponegoro (3rd ed., Vol. 3). Universitas Diponegoro. Gorenak, M., Edelheim, J. R., \& Brumen, B. (2020). The influence of organizational values on job satisfaction of employees. Human Systems Management, 39(3), 329-343. https://doi.org/10.3233/HSM190781

Gorenak, M., \& Ferjan, M. (2015). The influence of organizational values on competencies of managers. $E$ a $M$ : Ekonomie a Management, 18(1), 67-83. https://doi.org/10.15240/tul/001/2015-1006

Hair, J. F., Risher, J. J., Sarstedt, M., \& Ringle, C. M. (2019). When to use and how to report the results of PLS-SEM. European Business Review, 31(1), 2-24. https://doi.org/10.1108/EBR-11-20180203

Huang, K., Pearce, P., Guo, Q., \& Shen, S. (2020). Visitors' spiritual values and relevant influencing factors in religious tourism destinations. International Journal of Tourism Research, 22(3), 314324. https://doi.org/10.1002/jtr.2337
Nasir, C., Samad, I. A., Jannah, T. M., \& Sharudin, E. S. (2019). An Analysis of Moral Values in The Movie "Coco."

Vveinhardt, J., \& Gulbovaite, E. (2015). Questionnaire of Personal and Organizational Values Congruence for Employee Questionnaire of Personal and Organizational Values Congruence for Employee ( Q-POVC-115) Things that I value in life are very similar to the things that my organization values. July. 